\title{
QUALITY OF TOMATOES DURING STORAGE
}

\author{
Mara Duma $^{1 *}$, Ina Alsina ${ }^{2}$, Laila Dubova ${ }^{2}$, Ieva Erdberga ${ }^{2}$ \\ ${ }^{1}$ Department of Chemistry, Faculty of Food Technology, Latvia University of Agriculture, Liela iela 2, Jelgava, Latvia, \\ *e-mail:mara.duma@llu.lv \\ ${ }^{2}$ Institute of Soil and Plant sciences, Faculty of Agriculture, Latvia University of Agriculture, Liela iela 2, Jelgava, Latvia
}

\begin{abstract}
Tomatoes (Solanumly copersicum) are well known antioxidants, vitamins and other health beneficial compounds containing vegetable. Different qualitative and quantitative changes of chemical composition take place during tomato fruit ripening and storage. Research with the aim to evaluate the chemical composition (soluble solids, titratable acidity, vitamin C, total phenols) of tomatoes stored under ambient conditions was set up during year 2016. The study involved five tomato varieties cultivated and collected from greenhouse at green stage of ripening, then stored at room air temperature from $18.0{ }^{\circ} \mathrm{C}$ to $19.0{ }^{\circ} \mathrm{C}$ and relative humidity from $40.2 \%$ to $50.6 \%$ for 36 days. Collected data showed that the highest increase (in average for $12.6 \%$ ) of total soluble solids content was observed till 24 days of storage. It was found that content of vitamin C during ripening increased till the 24 day of the storage and it significantly depends on tomato variety (from $4.21 \%$ in variety Sakura F1 till $33.72 \%$ in variety Black Cherry F1). Further the content of vitamin $\mathrm{C}$ decreased and after 36 days of storage it was less than 7\% compared with the beginning of the experiment. The titratable acidity was significantly $(\mathrm{p}<0.05)$ different among the tomato varieties and depended on the stage of ripening. It varied

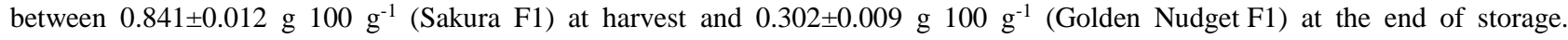
According to results the content of phenols during storage was variable and therefore the correlations were not observed.
\end{abstract}

Keywords: tomatoes, bioactive compounds, storage.

\section{Introduction}

Tomato (Solanumly copersicum) is second the most important vegetable crop worldwide (Pantheen, Chen, 2010), providing an important nutritional value to human diet. There is a growing interest in the beneficial health effects of tomato derived antioxidants (Carlsen et al., 2010; Korekar et al., 2011) and many scientific studies have been performed for demonstrating the benefits of tomatoes for human health (Burton-Freeman, et al. 2012; GómezRomero et al., 2010; Selli et al., 2014). These health benefits have been associated with nutritional value and bioactive phytochemicals along with carotenoids, vitamin $\mathrm{C}$, and the phenolic content of tomatoes (Mordente et al., 2011; Vallverdú-Queralt et al., 2011). The chemical composition of tomatoes depends on different factors such as variety, maturity, light, temperature, soil composition, fertilization, irrigation, handling practices, storage, and environmental conditions in which they are grown (Adubofuor et al., 2010).

Different qualitative and quantitative changes of chemical composition take place during tomato fruit ripening. The postharvest ripening stage has been associated with the production of flavour and aromatic compounds (Požrl, et al., 2010), an increase in ascorbic acid content and total soluble solids (Toor, Savage, 2006). Physicochemical profile of tomato fruits changes significantly over time and with the storage temperature (Okolie, Sanni, 2012). The optimal ripening condition for red tomatoes lies between $18{ }^{\circ} \mathrm{C}$ and $21^{\circ} \mathrm{C}$. Temperature below $5{ }^{\circ} \mathrm{C}$ and $10^{\circ} \mathrm{C}$ for longer than 7 and 14 days, respectively, prevents ripening and full colour development (Suslow, Cantwell, 2013).

The main antioxidants in tomatoes are carotenoids such as $\beta$-carotene, a precursor of vitamin $\mathrm{A}$, lycopene, vitamins such as ascorbic acid and phenolic compounds such as flavonoids and hydroxycinnamic acid derivatives (Kotkov et al., 2011; VallverdúQueralt et al., 2011). These compounds may play an important role through free-radical scavenging, metal chelation, inhibition of cellular proliferation, and modulation of enzymatic activity and signal transduction pathways (Crozier et al., 2009). Phenolics are important compounds for plants, due to acting as phytoalexins, contributors to plant pigmentation and reproduction as well as UV-light protectors. These compounds determined nutritional quality of fruits, vegetables, and other plants; they have been reported to be food preservatives as well as having a primary role in protection against pathological and degenerative disturbances (Ignat et al., 2011).

The aim of study was to evaluate the chemical composition (soluble solids, titratable acidity, vitamin $\mathrm{C}$, total phenols) of tomatoes stored under ambient conditions.

\section{Materials and Methods}

Investigations were carried out at the Latvia University of Agriculture, Institute of Soil and Plant Sciences.

Five tomato varieties Sunstream F1, Sakura F1, Black Cherry F1, Golden Nudget F1 and Rhianna F1 produced in the conventional way in greenhouse from $1^{\text {st }}$ of May till $15^{\text {th }}$ of September 2016 were studied. Sample fruits were harvested at green stage of maturity, each variety had a sample of 30 fruits per replication. Seven tomato fruits having similar size and colour of each variety were randomly selected for analysis, weighed, hand-rinsed with pure water, shaken to remove water, blotted with a paper towel, mixed, homogenized, and immediately analysed.

Tomatoes were stored under ambient conditions at room temperature from $18.0^{\circ} \mathrm{C}$ to $19.0^{\circ} \mathrm{C}$ and relative humidity from $40.2 \%$ to $50.6 \%$ for 36 days with four replications. On each sampling date (after 24 and 36 days), seven tomato fruits per experimental unit 
were randomly selected from each replication for analysis.

\section{Chemicals and spectral measurements}

All the reagents used were with the analytical grade from Sigma Aldrich, Germany. UV spectrophotometer UV-1800 (Shimadzu Corporation, Japan) was used for the absorbance measurements.

\section{Analytical methods}

The total soluble solids content was determined using a Refractometer A.KRÜSS Optronic Digital Handheld Refractometer Dr301-95, calibrated at $20^{\circ} \mathrm{C}$ with distilled water and expressed as ${ }^{\circ}$ Brix.

The content of vitamin $\mathrm{C}$ was determined titrimetrically using 2.6- dichlorphenolindophenol. For determination $2 \pm 0.001 \mathrm{~g}$ of tomato puree was quantitatively transferred in $100 \mathrm{~mL}$ tubes, added $50 \mathrm{~mL}$ of $1 \% \mathrm{HCl}$ and $5 \% \mathrm{HPO}_{3}$ mixture $(1: 1 \mathrm{v} / \mathrm{v})$ and mixed thoroughly. After 30 minutes solution was filtered through a filter paper No. $89^{\text {th }}$. For determination $10 \mathrm{~mL}\left(\mathrm{~V}_{\mathrm{a}}\right)$ of filtrate was titrated with 0.0005 molar solution of 2.6 dichlorphenolindophenol $\left(\mathrm{V}_{\text {titr }}\right)$. The content of vitamin $\mathrm{C}$ was calculating according to the equation (1):

Vitamin C $\left(\operatorname{mg~} 100 \mathrm{~g}^{-1}\right)=\frac{V_{\text {titr }} \cdot 0.044 \cdot V_{\text {total }} \cdot 100}{V_{a} \cdot \text { weight }}$ (1)

The titratable acidity was measured by the direct titration method with a strong alkaline solution. For determination $5 \pm 0.001 \mathrm{~g}$ of tomato puree was quantitatively transferred in $100 \mathrm{~mL}$ tubes, added $40 \mathrm{~mL}$ of pure water, mixed thoroughly. After 20 minutes solution was filtered through a filter paper No. $89^{\text {th }}$.

For determination $10 \mathrm{~mL}$ of filtrate was titrated with

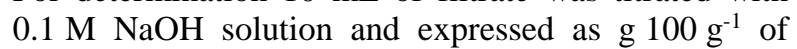
citric acid.

For total phenols extraction $1.0 \pm 0.001 \mathrm{~g}$ of finely ground tomato samples was weighed into volumetric flasks, $10 \mathrm{~mL}$ of extract, a mixture of methanol, distilled water and hydrochloric acid (79:20:1 v/v/v) was added. The vials were shaked at $20{ }^{\circ} \mathrm{C}$ for $60 \mathrm{~min}$ in the dark, then centrifuged for $10 \mathrm{~min}$ at $5000 \mathrm{rpm}$. The total phenolic content of the tomato samples was determined using the Folin-Ciocalteu reagent. To $0.5 \mathrm{~mL}$ of extract $2.5 \mathrm{~mL}$ of of Folin-Ciocalteu reagent (diluted 10 times with water) and, after 3 minutes $2 \mathrm{~mL}$ of sodium carbonate $\mathrm{Na}_{2} \mathrm{CO}_{3}\left(75 \mathrm{~g} \mathrm{~L}^{-1}\right)$ was added. The sample was mixed. After 1 hour of incubation at room temperature, the absorbance was measured at $765 \mathrm{~nm}$. Total phenols were expressed as gallic acid equivalents (GAE) $100 \mathrm{~g}^{-1} \mathrm{FW}$ of tomatoes.

\section{Statistical analysis}

Analyses were performed in three replicates and each one was measured for three repetitions. Data were expressed as mean of triplicates assay \pm standard deviation; for mathematical data processing the value of $\mathrm{p}<0.05$ was regarded as statistically significant. Oneway analysis of variance (ANOVA) was used to determine the significance of differences.

\section{Results and Discussion}

It has been shown that that skin and seeds are important contributors to the major antioxidant compounds of tomatoes (Toor, Savage, 2006), therefore chemical analyses were performed on whole tomatoes.

\section{Total soluble solids}

Significant $(\mathrm{p} \leq 0.05)$ difference was observed in total soluble solids content of tomato varieties during 36 days storage at ambient conditions. In tomato fruit samples the content of soluble solids (Figure 1) was found to be from $5.3{ }^{\circ}$ Brix (Sunstream F1 at harvest) till $8.3{ }^{\circ}$ Brix (Golden Nudget F1 and Rhianna F1 after 24 days of storage). The results indicated that the highest increase of soluble solids in all analysed tomato samples was observed till 24 days of storage, and after that time the values were decreased.

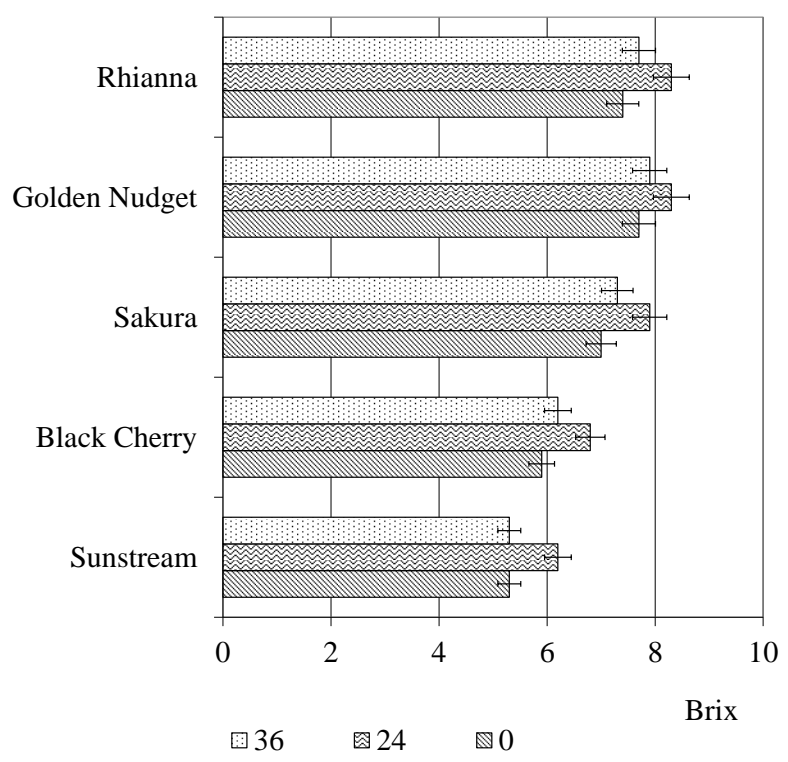

Figure 1. Total soluble solids content of tomato varieties depending on storage time (days)

These results are in agreement with Tigist et al. (2013), Ochoa-Velasco et al. (2016) and Talens et al. (2016).

\section{Content of vitamin $C$}

Vitamin C or ascorbic acid is one of the most important nutritional value parameter in fruits and vegetables (Tigist et al., 2013). The content of ascorbic acid at harvest was from $10.41 \mathrm{mg} 100 \mathrm{~g}^{-1}$ (Black Cherry F1)

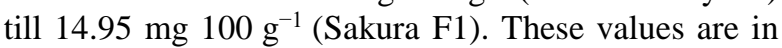
agreement with the concentration of ascorbic acid reported by Ochoa-Velasco et al. (2016), but less than findings of Vinha et al. (2013) and Kelebek et al. (2017).

In our study it was found that content of vitamin C during ripening increases till the 24 day of the storage (Figure 2). Moreover we could conclude that increase significantly $(\mathrm{p} \leq 0.05)$ depends on tomato variety from $4.21 \%$ variety Sakura F1 till $33.72 \%$ variety Black Cherry F1. 


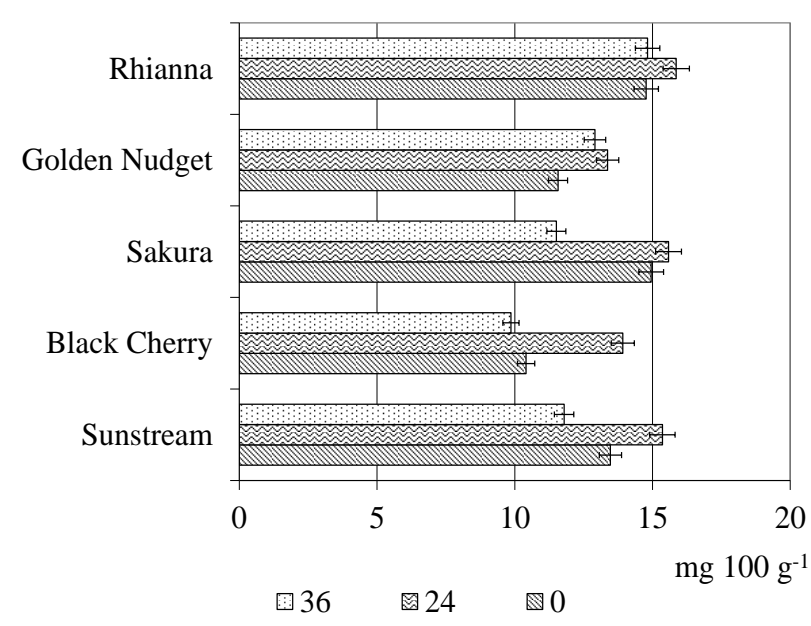

Figure 2 Ascorbic acid content of tomato varieties depending on storage time (days)

Further during storage reduction of values were observed. The content of vitamin $\mathrm{C}$ decreases and after 36 days of storage it was less than $7 \%$ compared with the beginning of experiment. Similarly Ajayi and Oderinde (2013) observed the decrease of vitamin C.

\section{Titratable acidity}

In tomato fruit samples the titratable acidity was significantly $(\mathrm{p} \leq 0.05)$ different among the tomato varieties and depends on time of storage (Table 1).

It was found that the titratable acidity at harvest was in the range of $0.61 \mathrm{~g} 100 \mathrm{~g}^{-1}$ till $0.84 \mathrm{~g} 100 \mathrm{~g}^{-1}$. Our findings are higher than results noted by Mladenovic et al. (2014) who determined that the total

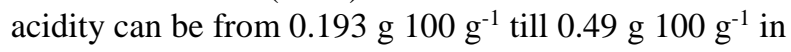
cherry tomato. After 24 days of storage at ambient conditions, the decrease of titratable acidity was observed from $30.5 \%$ (Golden Nudget F1) till $34.9 \%$ (Sunstream F1), but after 36 days the decrease was in average $24.7 \%$.

Table 1

Titratable acidity* of tomato varieties depending on storage time (days)

\begin{tabular}{lccc}
\hline \multirow{2}{*}{$\begin{array}{l}\text { Tomato } \\
\text { variety }\end{array}$} & \multicolumn{3}{c}{ Storage time (days) } \\
\cline { 2 - 4 } Sunstream & & $\mathbf{2 4}$ & $\mathbf{3 6}$ \\
F1 & $0.662 \pm 0.098$ & $0.431 \pm 0.025$ & $0.322 \pm 0.023$ \\
Black & & & \\
Cherry F1 & $0.816 \pm 0.102$ & $0.558 \pm 0.124$ & $0.404 \pm 0.045$ \\
Sakura F1 & $0.841 \pm 0.147$ & $0.569 \pm 0.073$ & $0.421 \pm 0.058$ \\
Golden & & & \\
Nudget F1 & $0.609 \pm 0.092$ & $0.423 \pm 0.056$ & $0.322 \pm 0.037$ \\
Rhianna F1 & $0.739 \pm 0.087$ & $0.508 \pm 0.101$ & $0.404 \pm 0.067$ \\
\hline$*$ expressed as citric acid g 100 g-1 $\mathrm{FW}$ of tomatoes
\end{tabular}

The decrease of titratable acidity during the storage could be related to higher respiration rate as ripening advances where organic acids are used as substrate in respiration process (Tigist et al., 2013).

Analysing obtained results we can conclude that tomato variety Rhianna F1 is more suitable for storage taking account the changes of titratable acidity (the decrease during storage $45.3 \%$ ), but the highest decreases was determined in tomato variety Sunstream
F1 (51.4\%). It is known that high levels of acidity are responsible for the stability of vitamin $\mathrm{C}$ during storage of fruits and vegetables (Vihna et al., 2013).

\section{Total phenols content}

According to obtained results (Table 2) the content of total phenols in analysed tomato samples during storage is variable and therefore the correlations were not observed.

It was find out that at green stage of maturity the richest tomato variety with phenolic compounds is Golden Nudget F1 (more than 40 mg GAE $100 \mathrm{~g}^{-1}$ ), but Black Cherry F1 contains about two times less these compounds.

Table 2

Total phenols content* of tomato varieties depending on storage period (days)

\begin{tabular}{lccc}
\hline \multirow{2}{*}{ Tomato variety } & \multicolumn{3}{c}{ Storage time (days) } \\
\cline { 2 - 4 } & $\mathbf{0}$ & $\mathbf{2 4}$ & $\mathbf{3 6}$ \\
\hline Sunstream F1 & $32.91 \pm 2.05$ & $25.31 \pm 1.25$ & $33.18 \pm 3.21$ \\
Black Cherry F1 & $23.63 \pm 1.95$ & $28.08 \pm 2.03$ & $35.62 \pm 2.69$ \\
Sakura F1 & $35.87 \pm 2.98$ & $35.75 \pm 2.93$ & $32.61 \pm 3.47$ \\
Golden Nudget F1 & $42.70 \pm 3.67$ & $31.67 \pm 3.07$ & $29.89 \pm 2.57$ \\
Rhianna F1 & $37.96 \pm 2.36$ & $32.39 \pm 2.95$ & $27.65 \pm 1.72$ \\
\hline
\end{tabular}

* expressed as mg gallic acid equivalents (GAE) $100 \mathrm{~g}^{-1} \mathrm{FW}$ of tomatoes

Determined total phenols content are in agreement with Vinha et al. (2013), but higher than results reported by Ochoa-Velasco et al. (2016),

The content of total phenols changes after 24 or 36 days of storage. We observed less phenolic content in tomato varieties Sakura F1, Golden Nudget F1 and Rhianna F1. One explanation could be that the decrease in levels of phenolic compounds observed at the end of storage could be due excess of rate of maturation (Vinha et al., 2013). In addition, other reasons could have been the binding of phenols to proteins and changes in chemical structures (Miranda et al., 2010). Phenolic substances have also been linked to the stability of vitamin $\mathrm{C}$ due to its protective effect (Vinha et al., 2013). Therefore, increased levels of total phenols might also be explained with higher contents of other antioxidants.

\section{Conclusions}

The major finding of this work was that content of antioxidants in tomatoes changed during storage at ambient conditions and it depended on tomato variety and duration. Content of vitamin $\mathrm{C}$ increased till the 24 day of the storage and it significantly depended on tomato variety (from $4.21 \%$ variety Sakura F1 till $33.72 \%$ variety Black Cherry F1). Further the content of vitamin $\mathrm{C}$ decreased and after 36 days of storage it was less than $7 \%$ compared with the beginning of the experiment. The titratable acidity was significantly $(\mathrm{p}<0.05)$ different among the tomato varieties and depended on the stage of ripening. It varied from

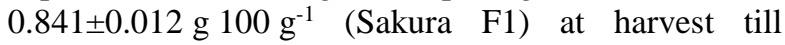

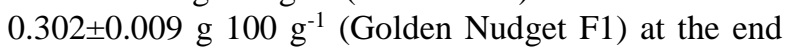
of storage. According to results the content of phenols 
during storage was variable and therefore the correlations were not observed.

\section{References}

1. Adubofuor J., Amankwah E.A., Arthur B.S., Appiah F. (2010) Comparative study related to physico-chemical properties and sensory qualities of tomato juice and cocktail juice produced from oranges, tomatoes and carrots. African Journal of Food Science, Vol. 4(7), p. 427-433.

2. Ajayi I.A., Oderinde R.A. (2013) Effects of different home storage conditions and preservation on some chemical constituents of tomato (Lycopersicon esculentum). Journal of Applied Chemistry, Vol. 4 (4), p. 19-29.

3. Burton-Freeman B., Talbot J., Park E., Krishnankutty S., Edirisinghe I. (2012) Protective activity of processed tomato products on postprandial oxidation and inflammation: A clinical trial in healthy weight men and women. Molecular Nutrition and Food Research, Vol. 56, p. 622-631

4. Carlsen M. H., Halvorsen B. L., Holte K., Bohn S. K., Dragland S., Sampson L., Blomhoff R. (2010) The total antioxidant content of more than 3100 foods, beverages, spices, herbs and supplements used worldwide. Nutrition Journal, Vol. 9 (3), p. 2-11.

5. Crozier A., Jaganath I. B., Clifford M. N. (2009) Dietary phenolics: Chemistry, bioavailability and effects on health. Natural Product Reports, Vol. 26(8), p. 1001-1043.

6. Gómez-Romero M., Segura-Carretero A., FernándezGutiérrez A. (2010) Metabolite profiling and quantification of phenolic compounds in methanol extracts of tomato fruit. Phytochemistry, Vol. 71, p. $1848-1864$.

7. Ignat I., Volf I., Popa V.I. (2011) A critical review of methods for characterisation of polyphenolic compounds in fruits and vegetables. Food Chemistry, Vol. 126, p. 1821-1835.

8. Kelebek H., Selli S., Kadiroglu P., Kola O., Kesen S., Ucar B., Çetiner B. (2017) Bioactive compounds and antioxidant potential in tomato pastes as affected by hot and cold break process. Food Chemistry, Vol. 220, p. $31-41$.

9. Korekar G., Stobdan T., Singh H., Chaurasia O. P., Singh S. B. (2011). Phenolic content and antioxidant capacity of various solvent extracts from Seabuckthorn (Hippophae rhamnoides L.) fruit pulp, seeds, leaves and stem bark. Acta Aliment, Vol. 40(4), p. 449-458.

10. Kotkov Z., Lachman J., Hejtmnkov A., Hejtmnkov K. (2011) Determination of antioxidant activity and antioxidant content in tomato varieties and evaluation of mutual interactions between antioxidants. LWT -Food Science and Technology, Vol. 44, p. 1703-1710.

11. Miranda M., Vega-Galvez A., LopezJ., Parada G., Sanders M., Aranda M. (2010) Impact of air-drying temperature on nutritional properties, total phenolic content and antioxidant capacity of quinoa seeds (Chenopodium quinoa Willd.). Industrial Crops and Products, Vol. 32(3), p. 258-263.
12. Mladenovic J., Acamovic-Dokovic G., Pavlovic R., Zdravkovic M., Girek Z., Zdravkovic J. (2014) The biologically active (bioactive) compounds in tomato (Lycopersicon esculentum Mill.) as a function of genotype. Bulgarian Journal of Agricultural Science, Vol. 20 (4), p. 877-882.

13. Mordente A., Guantario B., Meucci E. (2011) Lycopene and cardiovascular diseases: An update. Current Medicinal Chemistry, Vol. 18, p. 1146-1163.

14. Ochoa-Velasco C.E. , Valadez-Blanco R., SalasCoronado R., Sustaita-Rivera F., Hernández-Carlos B., García-Ortega S., Santos-Sánchez N.F. (2016) Effect of nitrogen fertilization and Bacillus licheniformis biofertilizer addition on the antioxidants compounds and antioxidant activity of greenhouse cultivated tomato fruits (Solanum lycopersicum L. var. Sheva). Scientia Horticulturae, Vol. 201, p. 338-345.

15. Okolie N. P., Sanni T. E. (2012) Effect of post harvest treatments on quality of whole tomatoes. African Journal of Food Science, Vol. 6(3), p. 70-76.

16. Pantheen D. R., Chen F. (2010) Genomics of fungal disease resistance in tomato. Current Genomics, Vol. 11(1), p. 30-39.

17. Požrl T., Žnidarčič D., Kopjar M., Hribar J., Simčič M. (2010) Change of textural properties of tomatoes due to storage and storage temperatures. Journal of Food Agriculture and Environment, Vol. 8(2), p. 292-296.

18. Selli S., Kelebek H., Ayseli M. T., Tokbas H. (2014) Characterization of the most aroma-active compounds in cherry tomato by application of the aroma extract dilution analysis. Food Chemistry, Vol. 165, p. 540-546.

19. Suslow T.V., Cantwell M., (2013) Tomato: Recommendations for Maintaining Postharvest Quality. Department of Plant Science, University of California, Davis. [accessed on 26.01.2017.]. Available:http://postharvest.ucdavis.edu/pfvegetable/Tom ato/

20. Talens P., Mora L., Bramley P. M, Fraser P. D. (2016) Antioxidant compounds and their bioaccessibility in tomato fruit and puree obtained from a DETIOLATED-1 (DET-1) down-regulated genetically modified genotype. Food Chemistry, Vol. 213, p. 735-741.

21. Tigist M., Workneh T.S., Woldetsadik K. (2013) Effects of variety on the quality of tomato stored under ambient conditions. Journal of Food Science and Technology, Vol. 50(3), p. 477-486.

22. Toor R.K., Savage G.P. (2006) Antioxidant activity in different fractions of tomatoes. Food Research International, Vol. 38, p. 487-494.

23. Vallverdú-Queralt A., Medina-Remón A., AndresLacueva C., Lamuela-Raventos R. M. (2011) Changes in phenolic profile and antioxidant activity during production of diced tomatoes. Food Chemistry, Vol. 126, p. 1700-1707.

24. Vinha A.F., Barreira S.V.P., Castro A., Costa A., Oliveira M.B.P.P. (2013) Influence of the Storage Conditions on the Physicochemical Properties, Antioxidant Activity and Microbial Flora of Different Tomato (Lycopersicon esculentum L.) Cultivars. Journal of Agricultural Science; Vol. 5 (2), p.118-128. 